\title{
MicroRNA-34a Attenuates Metastasis and Chemoresistance of Bladder Cancer Cells by Targeting the TCF1/LEF1 Axis
}

\author{
Xiaobing Liu ${ }^{\mathrm{a}}$ Xin Liu ${ }^{\mathrm{a}}$ Yuqi Wu $\mathrm{W}^{\mathrm{a}}$ Zhenqiang Fanga ${ }^{\mathrm{a}}$ Qingjian Wu \\ Chao Wu ${ }^{c}$ Yaxing $\mathrm{Hao}^{\mathrm{b}} \mathrm{Xia}$ Yang $^{\mathrm{b}}$ Jiang Zhao ${ }^{\mathrm{a}}$ Jia $\mathrm{Li}^{\mathrm{a}}$ Qingqing Wang ${ }^{\mathrm{a}}$ \\ Zhenxing Yang ${ }^{a}$ Jie $\mathrm{Xu}^{\mathrm{a}}$ Xiaoyan $\mathrm{Hu}^{\mathrm{a}}$ Mingjia Tan ${ }^{\mathrm{d}}$ Longkun $\mathrm{Li}^{\mathrm{a}}$
}

${ }^{a}$ Department of Urology, Xinqiao Hospital, Third Military Medical University, Chongqing, 'bInstitute of Immunology, Third Military Medical University, Chongqing, 'Department of Urology, People's Liberation Army No. 210 Hospital, Liaoning, China, dDivision of Radiation and Cancer Biology, Department of Radiation Oncology, University of Michigan, Ann Arbor, USA

\section{Key Words}

MiR-34a • Chemoresistance $•$ Epirubicin • Bladder cancer • BIU87 cells

\begin{abstract}
Background/Aims: Chemoresistance is largely responsible for relapses of bladder cancer during clinical therapy. However, the molecular mechanisms involved in the chemoresistance of bladder cancer are unclear. Growing evidence supports the theory that microRNAs (miRNAs) play an important role in chemotherapeutic drug resistance because they are downregulated in many malignancies that have been implicated in the regulation of diverse processes in cancer cells. More specifically, the extent and precise mechanism of the involvement of miR34as in chemoresistance to epirubicin (EPI) in the treatment of bladder cancer remains unclear. Methods: In this study, real-time quantitative polymerase chain reaction (PCR) was used to analyze the expression of miR-34a in bladder cancer cell line BIU87 and its EPI chemoresistant cell line BIU87/ADR. The miR-34a profiles in bladder cancer tissues were obtained from The Cancer Genome Atlas database. The effect of miR-34a on chemosensitivity was evaluated by cell viability assays, colony formation assays, and in vivo experimentation. Apoptosis and the cell cycle were examined by flow cytometry. A luciferase reporter assay was used to assess the target genes of miR-34a. Western blot and qPCR were used to analyze the expression of target proteins and downstream molecules. Results: The downregulation of miR-34a in bladder cancer serves as an independent predictor of reduced patient survival. The CCK-8 assay showed that miR-34a overexpression resulted in increased sensitivity to EPI, while miR34a downregulation resulted in chemoresistance to EPI in vitro. Moreover, it was found that miR-34a increased the sensitivity of BIU87/ADR cells to chemotherapy in vivo. The luciferase reporter assay ascertained that TCF1 and LEF1 are direct target genes of miR-34a. It was
\end{abstract}

\footnotetext{
Longkun Li, M.D., Ph.D. $\quad$ Department of Urology, Xinqiao Hospital, Third Military Medical University Chongqing, 400037 (China)

Tel. +86 23 68755623, Fax +86 23 68755623, E-Mail lilongk@hotmail.com, liuxiaobing10@tmmu.edu.cn
} 


\section{Cellular Physiology Cell Physiol Biochem 2018;48:87-98

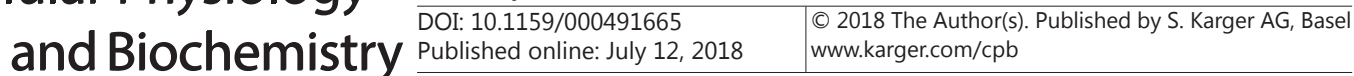 \\ Liu et al.: MicroRNA-34a Attenuates Metastasis and Chemoresistance in Bladder Cancer \\ Cells}

found that miR-34a increased chemosensitivity in BIU87/ADR cells by inhibiting the TCF1/ LEF1 axis. Conclusions: The results of this study indicate that miR-34a contributes to the chemosensitivity of BIU87/ADR by inhibiting the TCF1/LEF1 axis. Consequently, miR-34a is a determinant of BIU87 chemosensitivity and may therefore serve as a potential therapeutic target in bladder cancer treatment.

(C) 2018 The Author(s)

Published by S. Karger AG, Basel

\section{Introduction}

Bladder cancer ranks as the fourth and tenth leading cause of cancer-related deaths in males and females, respectively [1], and the incidence of bladder cancer continues to rise year by year [2]. The prognosis for patients with bladder cancer rests on factors such as histological subtype, tumor size, lymph node metastasis, and distant metastasis [3, 4]. Although epirubicin is commonly used to treat bladder cancer, resistance to the drug greatly inhibits its long-term curative effect [5] and the molecular mechanisms involved in chemoresistance of bladder cancer cells are unclear. It is therefore critical that effective molecular targets that could regulate bladder cancer invasion and chemoresistance are identified for the successful development of targeted therapies.

MicroRNA (miRNA) is a short, non-coding RNA (approximately 22 nucleotides in length) that binds to the $3^{\prime}$-untranslated region (3'-UTR) of mRNA and regulates gene expression by controlling mRNA translation or degradation [6,7]. MiRNAs are involved in various biological processes. In conjunction with their target genes, miRNAs play a critical role in tumor proliferation, differentiation, metastasis, and chemosensitivity [8] and miR34 a in particular functions as a tumor suppressor and is downregulated in many human cancers [9]. Furthermore, reduced expression of miR-34a is associated with chemotherapy resistance in a variety of cancers [10-13]. One of the mechanisms is the regulatory function of miR-34a in the p53 signaling pathway. miR-34a is considerably induced by p53 and its upregulation induces apoptosis, cell-cycle arrest and senescence and alters cancer cell chemosensitivity by directly targeting multiple genes in the p53 signaling pathway, such as Sirt-1, CDK6, E2F3 and Bcl2 $[14,15]$. In bladder cancer, miR-34a chemosensitizes bladder cancer cells during chemotherapy, regardless of the p53-Rb pathway status [12]. However, the regulatory mechanism of miR-34a in epirubicin-based bladder cancer chemotherapy is not clear and requires further investigation.

In this study, a series of in vitro and in vivo tests were performed, resulting in the discovery of consistently lower expression of miR-34a in BC tissues and epirubicin-resistant BIU87 cells. Overexpression of miR-34a significantly increased the sensitivity of BC cells to epirubicin treatment, as evidenced by greater numbers of apoptotic cells. Moreover, miR34a overexpression in BC xenograft tumors after miR-34a mimic transfection was found to contribute to the development of sensitivity to epirubicin treatment. Finally, our data indicate that miR-34a may confer chemosensitivity to epirubicin by reducing the levels of its target TCF1 and LEF1.

\section{Materials and Methods}

Protocol approval

All animal handling and experimental protocols were carried out in accordance with the Guide for the Care and Use of Laboratory Animals of the Third Military Medical University, China (approval no. SYXK20070002).

Patients and samples

The miR-34a expression profiles in BC tissues were obtained from the TCGA database (https://tcgadata.nci.nih.gov and https://genome-cancer.ucsc.edu). The prognostic value of miR-34a was analyzed using the TCGA portal. We used TCGA samples from patients at different stages of the disease to compare the 


\section{Cellular Physiology Cell Physiol Biochem 2018;48:87-98

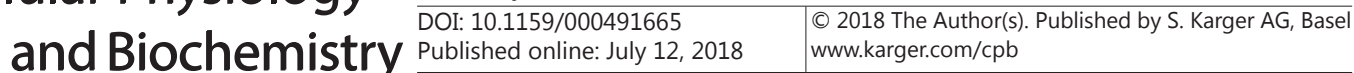 \\ Liu et al.: MicroRNA-34a Attenuates Metastasis and Chemoresistance in Bladder Cancer}

Cells

tissues in our analysis of miR-34a levels. Overall survival was determined by Kaplan-Meier analysis for patients with high or low levels of miR-34a.

\section{Cell culture and chemicals}

Human bladder cancer cell lines BIU87 and BIU87/ADR were purchased from Shanghai Meixuan Biological Technology Company (Shanghai, China) and cultured in RPMI 1640 media with $10 \%$ fetal bovine serum, penicillin, and streptomycin (Gibco, Carlsbad, CA, USA). The cell lines were maintained at $37^{\circ} \mathrm{C}$ and $5 \% \mathrm{CO}_{2}$ in a humidified incubator. EPI was purchased from Cayman Chemical (Ann Arbor, MI, USA). Cancer cell lines (BIU87 and BIU87/ADR) were seeded at a density of $3 \times 10^{5}$ per well in 6-well plates, incubated overnight, and subsequently treated with EPI for $48 \mathrm{~h}$. After induction, the cells were harvested for analysis.

The miR-34a mimic and miR-34a inhibitor were obtained from RiboBio (Guangzhou, China). Primary antibodies against GAPDH and TCF1, LEF1, E-cadherin, Bcl2, cyclin D1, CDK6, and c-MYC protein were obtained from Cell Signaling Technology (Danvers, MA, USA) and the primary antibodies against delta2 catenin were obtained from Abcam (Cambridge, UK)

\section{Real-time PCR assays}

Total RNA samples were extracted from the harvested cells using the RNAi (Dojindo Molecular Technologies, Kumanoto, Japan) according to the manufacturer's instructions. Quantitative reverse transcription PCR (qRT-PCR) was conducted using the method described by Duan et al [16].. For the detection of miRNA-34a, ADAM17, JAG1, Notch1, c-MY, cyclin D1, CDK6, and E-cadherin, $1 \mu \mathrm{g}$ of total RNA per sample was converted to cDNA using a Reverse SYBR Green PCR Kit (Qiagen, Valencia, CA, USA). GAPDH was used as the endogenous control for mRNA. For the detection of mRNA, the cDNA products were synthesized using a miScript Reverse Transcription Kit (Qiagen). The primers specific to miR-34a or the endogenous control U6 were purchased from Qiagen. The qRT-PCR was performed using a miScript SYBR Green PCR Kit (Qiagen). All reactions were performed in triplicate on a Bio-Rad C1000 thermal cycler (CFX-96 real-time PCR detection system; Bio-Rad, Hercules, CA, USA). The fold change of miRNA to mRNA expression was calculated according to the $2^{-\Delta \Delta c t}$ method. All primer sequences are provided in Table 1.

\section{Oligonucleotide transfection}

In the examination of transient transfection, miRNA mimics and inhibitors were transfected into BIU87 and BIU87/ADR cells using Lipofectamine 3000 Reagent (Invitrogen, Carlsbad, CA, USA), following the manufacturer's protocol. The miR-34a mimic and inhibitor, as well as the negative control, were obtained from RiboBio. All final concentrations of the miR-34a mimic and inhibitor and the negative control in the transfection system were $200 \mathrm{nM}$. After a period of $48 \mathrm{~h}$, the cells were collected for subsequent flow cytometry, western blotting, and qRT-PCR.

\section{Cell viability assay}

Cell proliferation was evaluated using a Cell-Counting Kit 8 (CCK8; Dojindo Molecular Technologies), following the manufacturer's instructions. BIU87 or BIU87/ADR cells (5000 per well) were cultured overnight in 96-well plates, and $10 \mu \mathrm{L}$ of CCK-8 solution was subsequently added to each well at the indicated time points after transfection. Cells were incubated for a further $2 \mathrm{~h}$ at $37^{\circ} \mathrm{C}$ in a $5 \% \mathrm{CO}_{2}$ incubator. The absorbance was measured at $450 \mathrm{~nm}$, using a Multiscan FC Microplate Photometer (Thermo Fisher Scientific, Rochester, NY, USA).

Clone formation assay

Transfected bladder cancer cells were plated in 6-well plates (500 cells/well) and cultured in RPMI1640 medium for 14 days. Proliferating colonies were stained with crystal violet and colonies consisting 


\section{Cellular Physiology Cell Physiol Biochem 2018;48:87-98

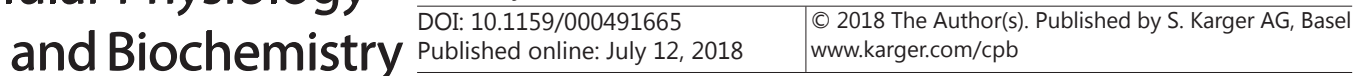 \\ Liu et al.: MicroRNA-34a Attenuates Metastasis and Chemoresistance in Bladder Cancer}

Cells

of $\geq 50$ cells were counted and photographed for statistical analysis. The colonies were observed using an inverted phase contrast microscope. All procedures were performed in triplicate.

\section{Western blotting}

Cells were analyzed in a RIPA buffer (1\% NP-40, 0.5\% sodium deoxycholate, $0.1 \%$ SDS in PBS). A complete protease inhibitor cocktail (Roche Diagnostics Corp., Indianapolis, IN, USA) was added to the lysis buffer before use. Protein concentration was determined using a Bio-Rad DC protein assay, and $30 \mu \mathrm{g}$ of total protein from cell lysates was subjected to SDS-PAGE and subsequently transferred to nitrocellulose membrane. The membrane was then blocked in 5\% non-fat milk in PBS overnight and incubated with primary antibody TCF1, LEF1, cleaved-caspase 3, Bcl2, CDK6, cyclin D1, c-myc, and E-cadherin (all from Cell Signaling Technology), delta2 catenin (Abcam), or $\beta$-actin (Cell Signaling Technology). After washing for $30 \mathrm{~min}$, secondary goat anti-mouse IgG (Vector Co., Burlingame, CA, USA) was applied to the nitrocellulose membrane in TBS-Tween for $1 \mathrm{~h}$ and washed again. The proteins of interest were detected using a Chemiluminescent HRP Antibody Detection Kit (Denville Scientific, South Plainfield, NJ, USA). The protein signals were captured using an electrochemiluminescent system (PerkinElmer Life Science, Boston, MA, USA).

\section{Cell cycle assay}

Cells were lysed and fixed in ice-cold $70 \%$ ethanol for $24 \mathrm{~h}$ at $4{ }^{\circ} \mathrm{C}$. Thereafter, propidium iodide (PI) was added and the cells were placed in the dark for $30 \mathrm{~min}$. Cells $\left(1 \times 10^{6}\right)$ were fixed using $70 \%$ ethanol at $-20^{\circ} \mathrm{C}$, incubated with propidium iodide (Invitrogen) for $30 \mathrm{~min}$ at $37^{\circ} \mathrm{C}$, and then analyzed using fluorescenceactivated cell sorting (FACS) flow cytometry (BD Biosciences, California, New Jersey, USA). Data analysis was performed using FlowJo software (version 9.3.2).

\section{Apoptosis assay}

The extent of apoptosis was determined by flow cytometry using an Annexin V/PI staining kit (BD Biosciences), according to the manufacturer's instructions. In brief, after collection, the cells were resuspended in $200 \mu \mathrm{L}$ binding buffer, and samples were subsequently incubated with $2 \mu \mathrm{L}$ annexin V-APC and $2 \mu \mathrm{L}$ 7-AAD in the dark for $15 \mathrm{~min}$ at room temperature (RT). They were then analyzed using flow cytometry. Data analysis was performed using FlowJo software (version 9.3.2).

\section{Wound healing assay}

A wound healing assay was used to assess the extent of cell migration and invasion. When cells reached a $90-95 \%$ confluence, a wound was generated by scratching the surface of the plates with a pipette tip. After removal of the floating cells, the adherent cells were incubated for $24 \mathrm{~h}$ until the wound healed. The gaps between the different time points were normalized one by one, immediately after scratching.

\section{Transwell cell invasion assay}

The transwell cell invasion assay was performed using a Cell Migration Kit with polycarbonate membrane inserts (8- $\mu \mathrm{m}$ pore size; Millipore, Billerica, MA, USA). Cells were serum-starved overnight in DMEM prior to the experiment. The lower chambers were filled with $1 \mathrm{~mL}$ of conditioned media. Cells $(4 \mathrm{x}$ $10^{4}$ ) were re-suspended in $200 \mu \mathrm{L}$ of DMEM and added to the upper chamber, before incubation at $37^{\circ} \mathrm{C}$ for $24 \mathrm{~h}$ to allow cell migration through the membrane. Thereafter, the cells were fixed and stained using $0.05 \%$ crystal violet. The numbers of cells that migrated from the upper to the lower chamber were counted from five random views in each experiment and each assay was performed three times.

\section{Dual-luciferase reporter assay}

In brief, 3' UTR segments of TCF1 and LEF1 were predicted to interact with miR-34a (https://www. targetscan.org). Luciferase reporter genes were successfully constructed using molecular cloning technology. The target sequence was inserted into a pGL3-Basic Vector (Promega Wisconsin, USA) to obtain pGL3-TCF13'-UTR and pGL3-LEF1-3'-UTR containing the miR-34a binding sequences (TCF1-3'-UTR and LEF1-3'-UTR sequences). The miR-34a modified BIU87/ADR cells were seeded at a density of $3 \times 10^{4}$ cells per well in 24-well plates for $24 \mathrm{~h}$. When the cells reached 60-70\% confluence, wild-type and mutant plasmids were co-transfected with miR-34a mimics or negative control (NC). Lipofectamine 3000 (Invitrogen) was used to 


\section{Cellular Physiology Cell Physiol Biochem 2018;48:87-98

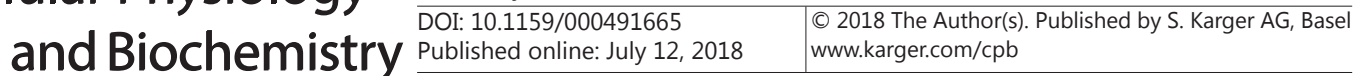 \\ Liu et al.: MicroRNA-34a Attenuates Metastasis and Chemoresistance in Bladder Cancer}

Cells

optimize transfection. Cells were collected at $48 \mathrm{~h}$ post-transfection. Luciferase activities were subsequently measured using the dual-luciferase reporter gene assay kit (Promega), according to the manufacturer's instructions. Luciferase activities were normalized to Renilla luciferase activity. Statistically significant differences between the treatment and control groups were determined using Student's t-test.

In vivo experiment in nude mice

The miR-34a mimic cells and their vector control cells were used to generate animal models. All animal handling and experimental protocols were carried out in accordance with the Guide for the Care and Use of Laboratory Animals of the Third Military Medical University, China (approval no. SYXK20070002). All efforts were made to mitigate animal suffering and to minimize the number of animals used. Four-week old BALB/c nude mice were used in this study and maintained at room temperature $\left(25 \pm 2{ }^{\circ} \mathrm{C}\right)$ under a standard $12 \mathrm{~h} / 12 \mathrm{~h}$ light-dark cycle in a specific, pathogen-free experimental animal room and fed a sterilized diet. For the subcutaneous tumor growth assay, $2 \times 10^{6}$ of the indicated cells in $0.1 \mathrm{~mL}$ of PBS were subcutaneously injected into 6-week-old female mice ( 8 mice per group). When the tumors reached a size of approximately $100 \mathrm{~mm}^{3}$, the mice were started on a treatment of either PBS or EPI $(6 \mathrm{mg} / \mathrm{kg}$ body weight). The treatment was administered every third day. After 3 weeks, the mice were sacrificed and tumor weights were measured. For lung and liver metastasis experiments, BC lung and liver metastatic models were generated by an injection of BC cells through the tail vein. Cells $\left(5 \times 10^{5}\right)$ were suspended in $0.1 \mathrm{~mL}$ of PBS and injected into the lateral tail veins of 6 -week-old female nude mice ( 8 mice per week). Three weeks after the injections, the mice were started on a treatment of either PBS or EPI ( $6 \mathrm{mg} / \mathrm{kg}$ body weight). Six weeks after the injections, all mice were sacrificed, and the lung and liver surface tumor foci were counted.

\section{H\&E staining}

Tumors excised from nude mice were fixed in $4 \%$ buffered paraformaldehyde for $24 \mathrm{~h}$ at room temperature, dehydrated through a graded series of ethanol solutions, embedded in paraffin wax, and cut into sections of $4 \mu \mathrm{m}$. Sections were subsequently stained with H\&E and observed under a light microscope.

\section{Statistical analysis}

Statistical analysis was performed using SPSS software (version 19.0). All data are expressed as means \pm SD, unless otherwise stated. Comparisons between two groups were performed using a two-tailed unpaired t-test, while comparisons of three or more groups were performed using one-way analysis of variance (ANOVA). Differences between tumor volumes were determined using a two-way ANOVA. Overall survival analysis was performed using the Kaplan-Meier method. Statistical significance was set at $\mathrm{p}<0.05$.

\section{Results}

Downregulated expression levels of miR-34a in bladder cancer tissues correlate with tumor progression

First, we compared miR-34a expression levels at different stages of bladder cancer in the TCGA dataset (Fig. 1A). Notably, miR-34a expression was lower in the late stages of the disease than in the early stages, indicating that miR-34a is a tumor suppressor in bladder cancer. In addition, the Kaplan-Meier survival analysis demonstrated that the BC patient group with a lower level of miR-34a had a lower survival rate than the group with a high level of miR-34a (Fig. 1B). Further investigations into the impact of EPI chemotherapy on the expression of miR-34a in BC cells were subsequently conducted, using BIU87 and BIU87/ ADR cells, and qRT-PCR analysis showed that miR-34a expression was significantly lower in BIU87/ADR cells than in BIU87 cells (Fig. 1C). Together, these results suggest that reduced expression of miR-34a indicates a poor prognosis and may be involved in the stimulation of BC metastasis and chemoresistance.

Inhibition of miR-34a contributes to EPI chemoresistance and metastasis in vitro

As indicated in Fig. 1D, qRT-PCR analysis confirmed a high level of miR-34a expression after transfection. To determine the effect of miR-34a on the proliferation of BC cell lines, 


\section{Cellular Physiology

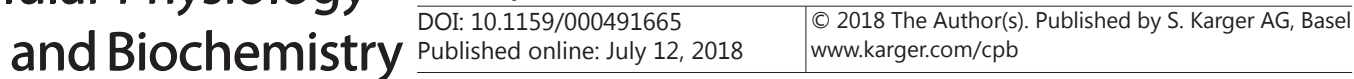 \\ Liu et al.: MicroRNA-34a Attenuates Metastasis and Chemoresistance in Bladder Cancer Cells}

Fig. 1. Downregulated expression level of miR-34a in bladder cancer tissues correlates with tumor progression. (A) Levels of miR-34a in bladder cancer patients at different stages compared with early stage subjects in the TCGA database. (B) KaplanMeier analysis of overall survival in bladder cancer patients with low or high miR-34a levels. (C) Levels of miR-34a in BIU87 and BIU87/ADR cells. (D) Levels of miR-34a in BIU87 and BIU87 miR-34a inhibitors and BIU87/ADR and BIU87/ADR miR-34a mimics. ${ }^{*} \mathrm{p}<0.05 ;{ }^{* *} \mathrm{p}<0.01 ;{ }^{* * *} \mathrm{p}<0.001$.

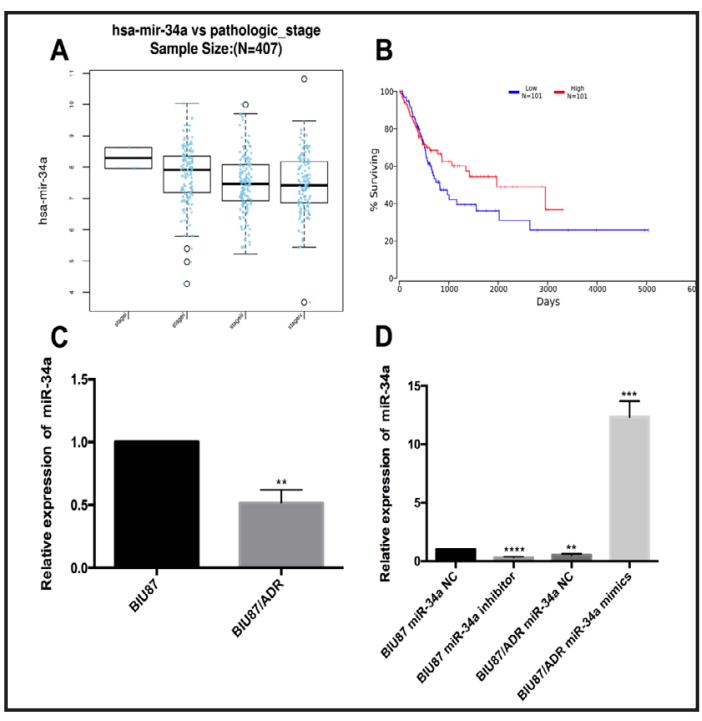

Fig. 2. miR-34a attenuates bladder cancer proliferation in vitro. (A) Inhibition of miR-34a reduced EPI-induced cell growth in BIU87cells. (B) Overexpression of miR-34a enhanced EPI-induced cell growth in BIU87/ADR cells. (C, E) Inhibition of miR-34a increased bladder cancer migration in BIU87 cells. (D, F) Overexpression of miR-34a decreased bladder cancer migration in BIU87/ADR cells. Morphological analysis of (G, I) BIU87 cells compared with BIU87 miR-34a inhibition and $(\mathrm{H}$, J) BIU87/ADR cells compared with the BIU87/ADR miR-34a mimic. ${ }^{*} \mathrm{p}<0.05 ;{ }^{* *} \mathrm{p}<0.01 ;{ }^{* * *} \mathrm{p}<0.001$.

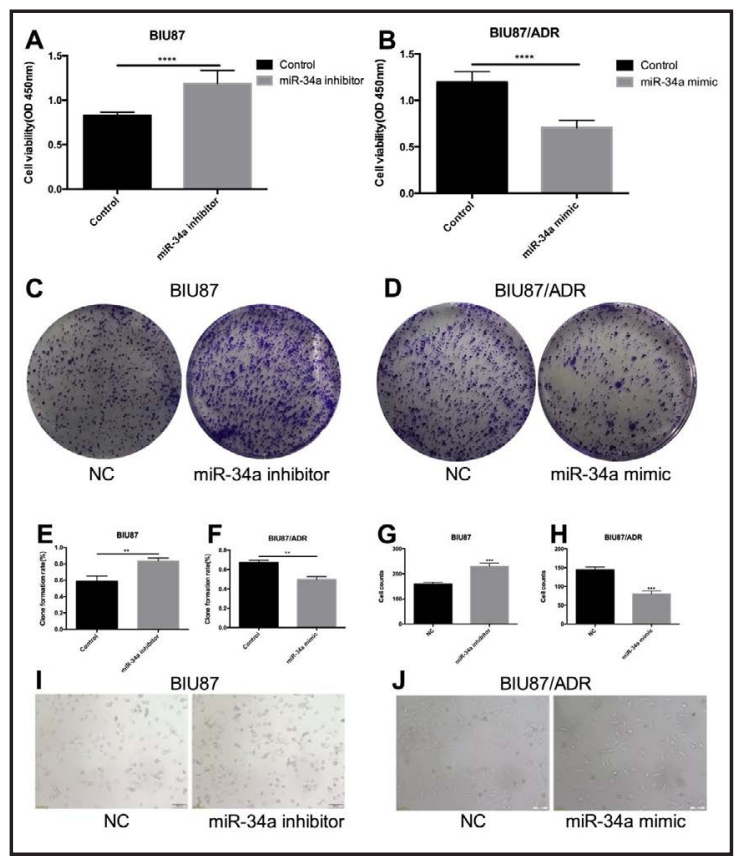

BIU87 and BIU87/ADR cells were transfected with miR-34a inhibitor and miR-34a mimics, respectively. The proliferation of BIU87 cells $48 \mathrm{~h}$ after transfection was significantly lower than that of the miRNA negative control (Fig. 2A and 2B). The effect of miR-34a was also tested via colony formation, another type of proliferation assay (Fig. 2C, D, E, and F). Here, the inhibition of miR-34a significantly promoted colony formation in BIU87 cells, whereas overexpression of miR-34a significantly decreased colony formation in BIU87/ADR cells. Morphological analysis of the cells showed similar changes in both BIU87 and BIU/ADR cells, characterized by cell volume and concomitant shrinking (Fig. 2G, H, I, and J). Additionally, an apoptosis assay was conducted using flow cytometry to determine whether the effects of miR-34a on cell proliferation were related to apoptosis. BIU87 cells were first transfected with a miR-34a inhibitor for a period of $24 \mathrm{~h}$ and treated with EPI for another $24 \mathrm{~h}$. The results showed that ectopic miR-34a inhibition decreased EPI-induced cellular apoptosis (Fig. 3A and B). Similar results were obtained from BIU87/ADR (Fig. 3C and D). Next, BIU87 cells were first transfected with miR-34a inhibitor for $24 \mathrm{~h}$ and treated with EPI for another 
Fig. 3. miR-34a attenuates chemoresistance and metastasis in bladder cancer cells. Flow cytometry analysis shows that (A, C) low levels of miR-34a protect cells from apoptosis in BIU87 cells and (B, D) high levels of miR-34a promote cell apoptosis in BIU87/ADR cells. Cell cycle assays show that $(\mathrm{E}, \mathrm{G})$ low levels of miR-34a promote the cell cycle through reduced G1/G0 arrest and $(\mathrm{F}, \mathrm{H})$ high levels of miR-34a induce G1/G0 arrest in BIU87/ ADR cells. Wound healing assays show that (I, K) low levels of miR34 a promote BIU87 cell migration and $(\mathrm{J}, \mathrm{L})$ high levels of miR-34a impair BIU87/ADR cell migration. Transwell migration assays show that $(\mathrm{M}, 0)$ inhibition of miR-34a promotes BIU87 cell migration and $(\mathrm{N}, \mathrm{P})$ overexpression of miR-34a inhibits BIU87/ADR cell migration. ${ }^{*} \mathrm{p}<0.05 ;{ }^{* *} \mathrm{p}<0.01 ;{ }^{* * *} \mathrm{p}<0.001$.
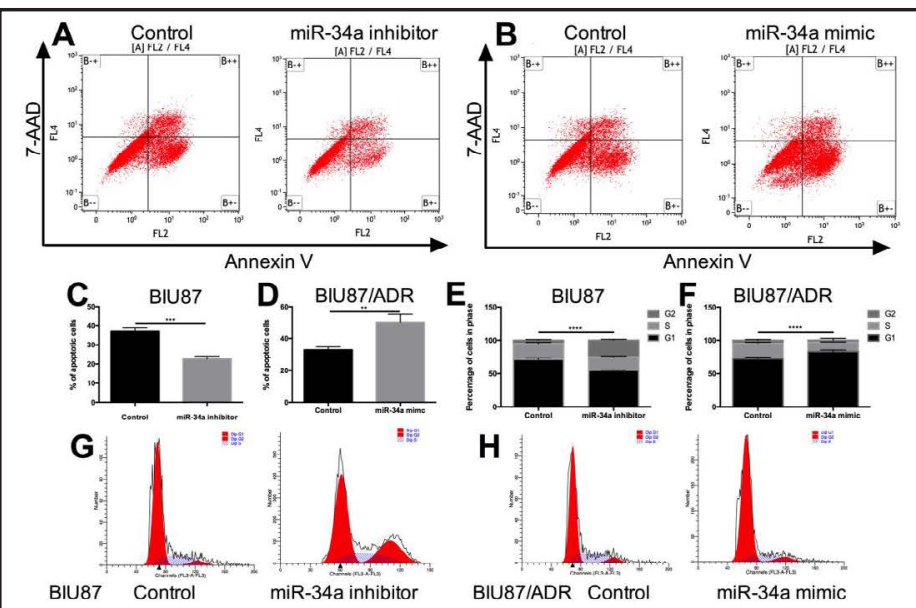

Fo 1 iso BIU87/ADR
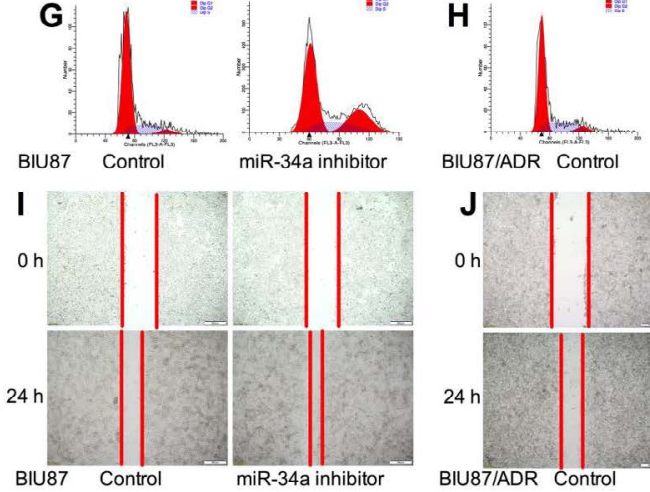

BIU87/ADR Control
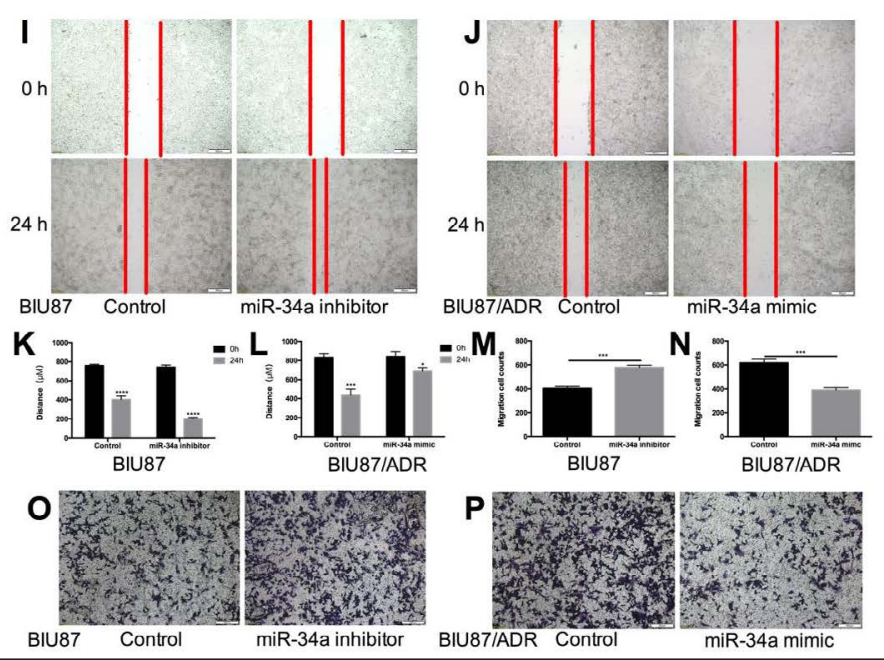

$24 \mathrm{~h}$ to determine whether the effects of miR-34a on cell proliferation were related to the cell cycle. The results showed that ectopic miR-34a inhibition induced G1/G0 arrest, which indicated cell cycle arrest (Fig. 3E, F, G, and H). Collectively, the results show that cells with miR-34a downregulation are clearly resistant to EPI treatment in BC cells.

The following information should be considered when investigating whether the reduced expression of miR-34a was involved in BC metastasis. As shown in Fig. 3, in the in vitro wound healing and the transwell assays, the inhibition of miR-34a can promote significant cell invasion of BIU87 cells (Fig. 3I, K, M, and O), while overexpression of miR-34a reduce significant cell invasion of BIU87/ADR cells (Fig. 3J, L, N, and P). These results clearly demonstrate that cells with downregulated miR-34a are stimulated by BC metastasis.

miR-34a inhibits BC metastasis and chemoresistance through directly regulated TCF1 and LEF1 expressions

To investigate the association between miR-34a and TCF1/LEF1 expression, the expression of TCF1/LEF1 was examined in relation to miR-34a overexpression and inhibition in BIU87/ADR and BIU87 cells at both mRNA and protein levels, respectively (Fig. 4A, B, and C). Furthermore, to investigate the underlying mechanism of miR-34a and TCF1/LEF1 on bladder cancer cell metastasis and chemoresistance, miRNA target prediction algorithms (http://targetscan.org and http://microrna.org) were used to screen miR-34a target genes, with TCF1 and LEF1 identified as tentative targets of miR-34a (Fig. 4D and E). Notably, previous studies have shown that the Wnt/ $\beta$-Catenin pathway correlates closely with bladder cancer progression, metastasis, and chemoresistance [17-19]. To determine whether the regulation 
Fig. 4. miR-34a inhibits $\mathrm{BC}$ metastasis and chemoresistance by directly regulating TCF1 and LEF1 expression. (A) Western blot for TCF1 and LFF1 expression in BIU87 and BIU87/ADR cells. (B, C) qPCR for TCF1 and LEF1 mRNA expression in BIU87 and BIU87/ADR cells. Bioinformatics analysis shows that miR-34a binds to 3'UTR of (D) TCF1 mRNA and (E) LEF1 mRNA. (F) miR-34a-modified BIU87 cells were transfected with $1 \mu \mathrm{g}$ of TCF1-3'UTR luciferase reporter plasmid, and the luciferase activities were quantified. (G) miR-34a-modified BIU87 cells were transfected with $1 \mu \mathrm{g}$ of LEF1-3'UTR luciferase reporter plasmid, and the luciferase activities were quantified. ${ }^{*} \mathrm{p}<0.05 ;{ }^{* *} \mathrm{p}<0.01 ;{ }^{* * *} \mathrm{p}<0.001$.

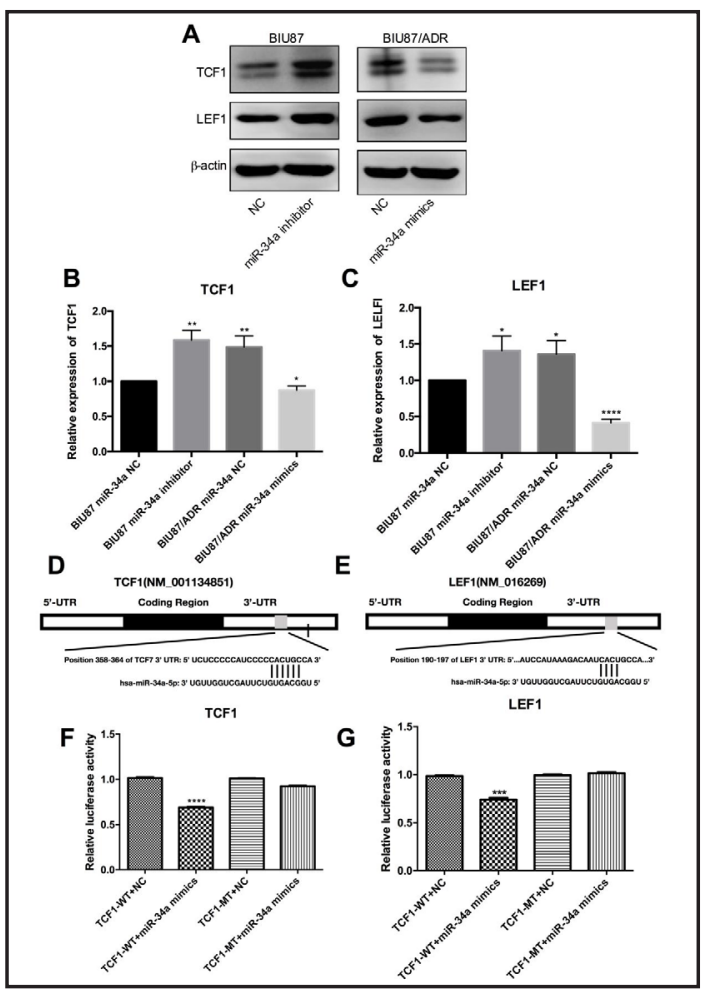

Fig. 5. miR-34a negatively regulates Wnt/ $\beta$-Catenin signaling pathways. (A) Western blot for Wnt/ $\beta$-Catenin signaling pathways in BIU87 and BIU87/ ADR cells. qPCR for $(B, C) \mathrm{Bcl} 2$ mRNA expression, (D, E) CDK6 mRNA expression, (F, G) c-myc mRNA expression, $(\mathrm{H}, \mathrm{I}) \mathrm{E}$-cadherin mRNA expression, and (J, K) delta2 catenin mRNA expression. ${ }^{*} \mathrm{p}<0.05 ;{ }^{* *} \mathrm{p}<0.01 ;{ }^{* * *} \mathrm{p}<0.001$.

of TCF1-luciferase and LEF1luciferase expression is dependent on the binding of their complementary $3^{\prime}$ UTR sequences to the miR$34 \mathrm{a}$ seed sequence, a 3-nt mutation was inserted into the TCF1 3'UTR and LEF1 3'UTR. The results revealed that the overexpression of miR-34a significantly repressed the luciferase activity associated

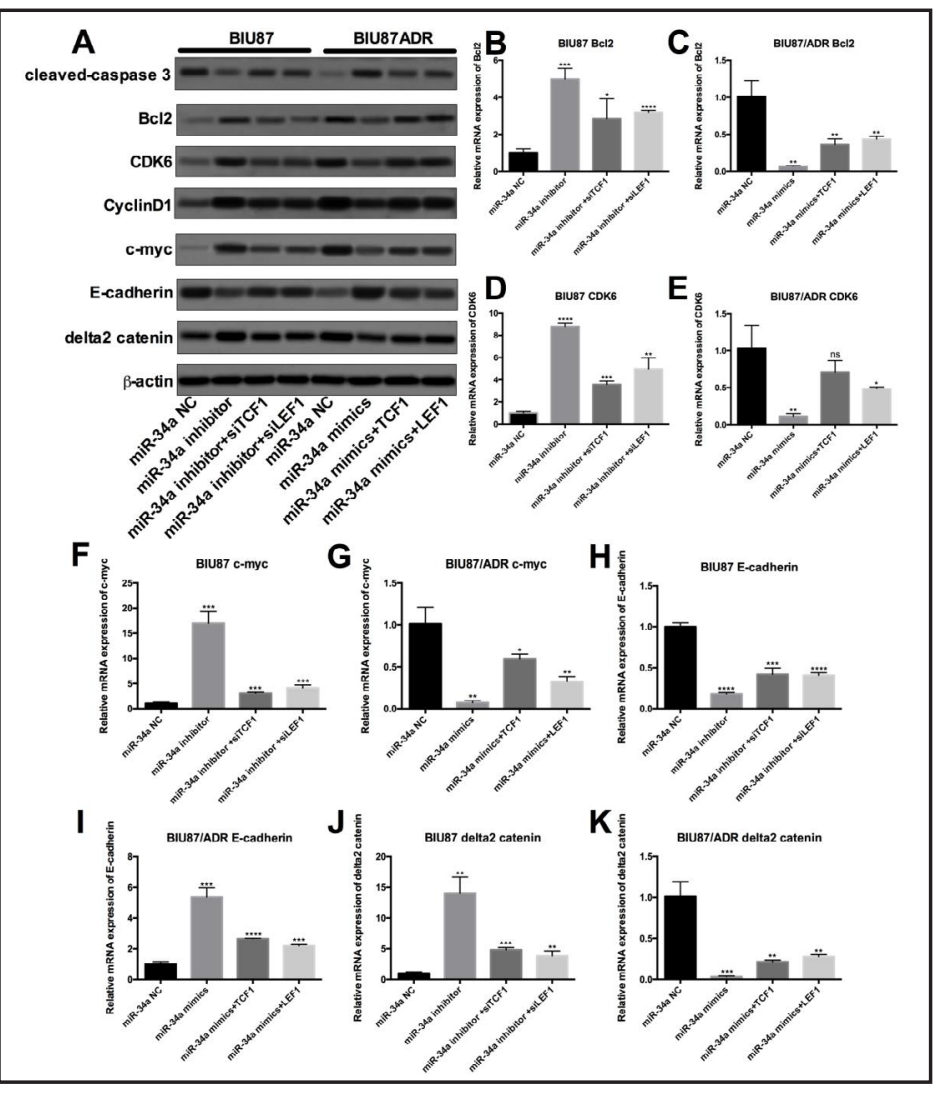
with the wild-type $3^{\prime} \mathrm{UTR}$, while the $3^{\prime}$ UTR mutation completely abrogated the effect of miR-34a overexpression on luciferase activity in BIU87 cells (Fig. 4F and G). Cumulatively, these findings suggest that 


\section{Cellular Physiology Cell Physiol Biochem 2018;48:87-98 and Biochemistry \begin{tabular}{c|c} 
DOI: 10.1159/000491665 \\
Published online: July 12, 2018 & $\begin{array}{l}\text { O } 2018 \text { The Author(s). Published by S. Karger AG, Basel } \\
\text { www.karger.com/cpb }\end{array}$
\end{tabular} \\ Liu et al.: MicroRNA-34a Attenuates Metastasis and Chemoresistance in Bladder Cancer

miR-34a negatively regulates the expression of TCF1/LEF1 axis by directly targeting the 3'UTR sequence.

A rescue experiment was performed to test whether miR-34a negatively regulates TCF1/LEF1 downstream signal or protein expression through direct targeting of the TCF1/ LEF1 axis. The Wnt/ $\beta$-Catenin signaling pathways protein, including cleaved-caspase 3 (Fig. 5A), Bcl2 (Fig. 5A, B, and C), CDK6 (Fig. 5A, D, and E), cyclin D1 (Fig. 5A), C-myc (Fig. 5A, F, and G), E-cadherin (Fig. 5A, H, and J), and delta2 catenin (Fig. 5A, J, and K), were tested by qPCR or western blot. Our results suggest that the restoration of miR-34a can upregulate cleaved-caspse 3 and anti-metastatic protein E-cadherin and downregulate Bcl2, CDK6, cyclin D1, c-myc, and delta 2 catenin expression in BIU87/ADR cells, while overexpression of TCF1/LEF1 can rescue the properties of bladder cancer cells and lead to metastasis. The cumulative data confirms that the restoration of miR-34a and inhibition of TCF1/LEF1 reduces the properties and chemoresistance of bladder cancer cells.

Overexpression of miR-34a is involved in the development of EPI chemosensitivity and metastasis in vivo

BIU87/ADR cells were examined to test the effects of miR-34a overexpression on the chemosensitivity of BIU87 cells. A consistently lower tumor volume was observed in tumors with miR-34a overexpression than in those with empty vectors under EPI administration, particularly on day 21 after the initiation of EPI treatment (Fig. 6A and B). At the end of the experimental period, the mean wet weights of the tumors were significantly lower in the miR-34a transfected group than in the empty vector control group ( $\mathrm{p}<0.05$; Fig. 6C). Further tests for the involvement of miR-34a in metastasis and EPI resistance in vivo involved

Fig. 6. miR-34a attenuates bladder cancer chemoresistance and metastasis in vivo. (A) Representative tumors show significantly larger xenografts with BIU87/ADR than in the miR$34 \mathrm{a}$ overexpression group and BIU87 group. (B) Increased tumor volumes over time in EPI-treated mice, especially for xenografted BIU87/ADR tumors.

(C) Significantly greater tumor weight at the end of the treatment period (28 days after bladder cancer cell injection) in the BIU87/ADR group. Data are shown as means \pm SD (n = $6, \mathrm{P}<0.05)$. (D, F) Overexpression of miR-34a reduced bladder cancer lung metastasis in vivo. The mice were sacrificed 28 days after cell injection, and lung surface nodules were counted under microscopy. (E, G) Overexpression of miR-34a reduced bladder cancer liver metastasis. The mice were sacrificed 28 days after cell injection, and liver surface nodules

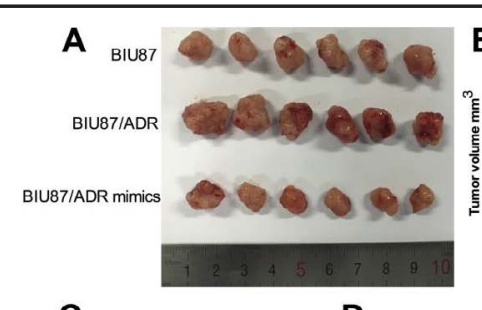

C
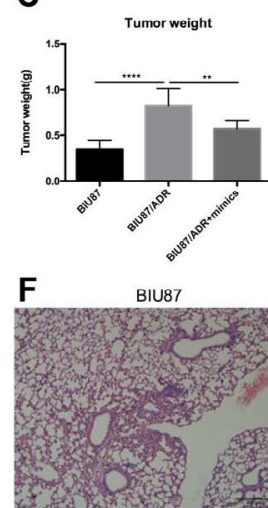

D
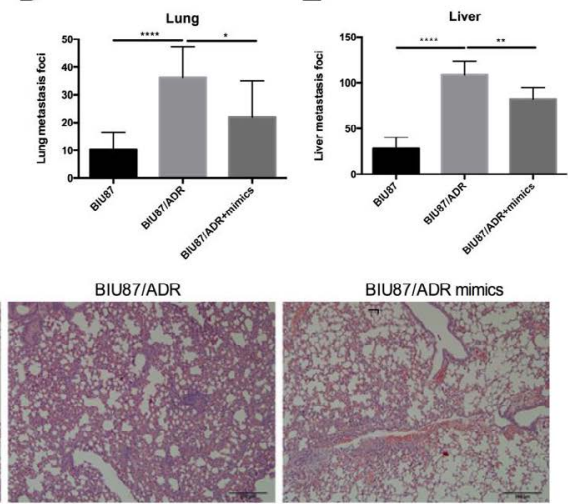

G
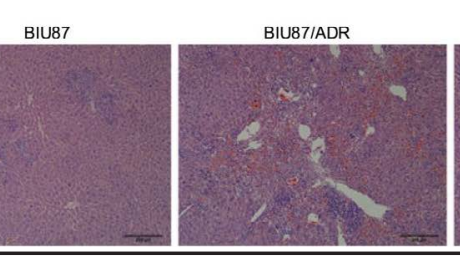
BIU87/ADR mimics

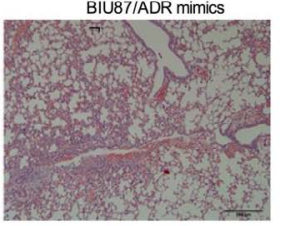

BIU87/ADR mimics

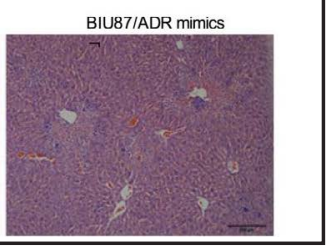
were counted. ${ }^{*} \mathrm{p}<0.05 ;{ }^{*} \mathrm{p}<0.01$; $* * * \mathrm{p}<0.001$. 
injections into athymic nude mice with the cell lines grown as xenograft tumors. The nude mice were sacrificed 6 weeks later, and surface tumor nodules were counted on the lung and liver metastasis models. The results confirm that the overexpression of miR-34a inhibits BIU87/ADR cell lung and liver metastasis (Fig. 6D, E, F, and G). Therefore, higher expression of miR-34a is also associated with metastasis and EPl chemosensitivity in vivo.

\section{Discussion}

EPI is a chemotherapeutic agent commonly used to treat multiple malignancies, including bladder cancer, but there are currently no known markers for either response or resistance to treatment. The development of new molecules for bladder cancer screening and treatment is therefore urgently required [20]. Molecular profiling of miRNAs may assist in the development of companion diagnostics in the clinic to identify subgroups of patients most likely to develop metastasis or respond to chemotherapy [21, 22]. By directly targeting protein-coding genes, miRNAs are able to inhibit the genes necessary for signaling pathways or drug-induced apoptosis [22]. In recent years, microRNAs have attracted increasing attention, with multiple miRNAs-including miR-195 [23], miR-124 [24], miR-1-3p [25], miR-218[26], and miR-222-3p [27]—highlighted as critical components in the control of proliferation, metastasis, and drug resistance in bladder cancer $[28,29]$. The present study examined the influence of EPI on miR-34a expression and its target genes by using in vitro/ in vivo assays and bladder cancer cells. Notably, our data implies that a miR-34a mimic is a potential therapeutic agent for treating chemoresistant bladder cancer.

miR-34a is downregulated in many types of cancer and acts as a critical tumor suppressor by targeting multiple oncogenes that modulate cancer-related processes, such as cell proliferation, apoptosis, metastasis, and chemoresistance [30]. Moreover, previous studies have indicated that miR-34a inhibits migration and invasion via Notch1 and CD44 and induces chemosensitivity to cisplatin treatment, regardless of the $\mathrm{p} 53-\mathrm{Rb}$ pathway in bladder cancer $[12,31,32]$. In the present study, BIU87/ADR was obtained from BIU87 through treatment with EPI. Thereafter, a series of in vitro and in vivo studies provided evidence that the reduced expression of miR-34a contributes significantly to lung and liver metastasis and chemoresistance through the inhibition of apoptosis and Wnt/ $\beta$-Catenin signaling pathways in bladder cancer. Accumulating evidence shows that the induction of apoptosis and activation of Wnt/ $\beta$-Catenin signaling pathways dramatically suppress tumor growth, metastasis, and chemoresistance, confirming that miR-34a can regulate apoptosis through Wnt/ $\beta$-catenin signaling pathways. Indeed, some studies have revealed that miR34 a alters apoptosis via direct BCL2 targeting $[33,34]$. Our findings clearly indicate that the overexpression of miR-34a can significantly enhance EPI-induced apoptosis and Wnt/ $\beta$-Catenin signaling pathway inhibition. Furthermore, bladder cancer cell metastasis is dramatically inhibited in vitro and in vivo, indicating that restoration of miR-34a may be a useful strategy for the treatment of metastasis and chemoresistance in bladder cancer patients.

TCF1 and LEF1 are two important interactions of activated Wnt/ $\beta$-catenin in nuclei. Activation of the canonical Wnt/ $\beta$-catenin signaling pathway is frequently involved in the development of tumors, include colorectal cancer, malignant melanoma, and several other tumor types [35]. Indeed, our study confirmed the association between miR-34a and TCF1/ LEF1 in the treatment of bladder cancer by qRT-PCR and western blot analysis. Moreover, the dual-luciferase reporter gene experiments conducted in this study show that miR-34a directly targets the $3^{\prime}$ UTR of TCF1 and LEF1.

In summary, this study combined clinical and experimental research to determine the role and clinical significance of miR-34a in the progression of bladder cancer. The miR-34a-mediated regulation of TCF1/LEF1 is involved in bladder cancer metastasis and chemoresistance; however, the restoration of miR-34a and inhibition of TCF1/LEF1 was found to reduce the properties and chemoresistance of bladder cancer cells both in vivo 


\section{Cellular Physiology Cell Physiol Biochem 2018;48:87-98 \begin{tabular}{l|l} 
DOI: 10.1159/000491665 & $\begin{array}{l}\text { O } 2018 \text { The Author(s). Published by S. Karger AG, Basel } \\
\text { www.karger.com/cpb }\end{array}$
\end{tabular} \\ Liu et al.: MicroRNA-34a Attenuates Metastasis and Chemoresistance in Bladder Cancer

and in vitro. In addition, miR-34a is one of the master tumor suppressor miRNAs, and the miR-34a/TCF1/LEF1 axis plays a crucial role in the survival of bladder cancer cells. Thus, modulation of the miR-34a and TCF1/LEF1 axis may serve as a novel therapeutic strategy for drug-resistant $\mathrm{BC}$ by increasing chemosensitivity and shifting $\mathrm{BC}$ therapy from conventional methods to targeted therapies.

\section{Acknowledgements}

LL, JX, and ZY conceived and designed the experiments; XL, LL, and YW performed the experiments; LL, ZF, QW, YH, and XY analyzed the data; QW and XH contributed reagents, materials, and analysis tools; and LL and XL wrote the paper.

This work was supported partly by the National Natural Science Foundation of China (81470989) and partly by key clinical research projects of the Second Affiliated Hospital, Third Military Medical University (2014YLC28 and 2015YLC06). We thank Dr. Qingjian Wu for constructive comments and editing the manuscript. We are grateful to the authors and publications that were not cited in this paper due to space restrictions.

\section{Disclosure Statement}

The authors declare to have no conflict of interests.

\section{References}

1 Chen Q Chong T, Yin J, Luo P, Deng A: Molecular events are associated with resistance to vinblastine in bladder cancer. Cell Mol Biol (Noisy-le-grand) 2015;61:33-38.

-2 Siegel R, Ma J, Zou Z, Jemal A: Cancer statistics, 2014 CA Cancer J Clin 2014;64:9-29.

-3 Reddy OL, Cates JM, Gellert LL, Crist HS, Yang Z, Yamashita H, Taylor JA, 3rd, Smith JA, Jr., Chang SS, Cookson MS, You C, Barocas DA, Grabowska MM, Ye F, Wu XR, Yi Y, Matusik RJ, Kaestner KH, Clark PE, DeGraff DJ: Loss of FOXA1 Drives Sexually Dimorphic Changes in Urothelial Differentiation and Is an Independent Predictor of Poor Prognosis in Bladder Cancer. Am J Pathol 2015;185:1385-1395.

-4 Szarvas T, Laszlo V, Vom Dorp F, Reis H, Szendroi A, Romics I, Tilki D, Rubben H, Ergun S: Serum endostatin levels correlate with enhanced extracellular matrix degradation and poor patients' prognosis in bladder cancer. Int J Cancer 2012;130:2922-2929.

5 Liu CW, Wu YT, Lin KJ, Yu TJ, Kuo YL, Chang LC: A Hydrogel-Based Epirubicin Delivery System for Intravesical Chemotherapy. Molecules 2016;21

6 Caldas C, Brenton JD: Sizing up miRNAs as cancer genes. Nat Med 2005;11:712-714.

7 Calin GA, Croce CM: MicroRNA signatures in human cancers. Nat Rev Cancer 2006;6:857-866.

-8 Blower PE, Chung JH, Verducci JS, Lin S, Park JK, Dai Z, Liu CG, Schmittgen TD, Reinhold WC, Croce CM, Weinstein JN, Sadee W: MicroRNAs modulate the chemosensitivity of tumor cells. Mol Cancer Ther 2008;7:1-9.

-9 Lodygin D, Tarasov V, Epanchintsev A, Berking C, Knyazeva T, Korner H, Knyazev P, Diebold J, Hermeking H: Inactivation of miR-34a by aberrant CpG methylation in multiple types of cancer. Cell Cycle 2008;7:25912600.

10 Wiggins JF, Ruffino L, Kelnar K, Omotola M, Patrawala L, Brown D, Bader AG: Development of a lung cancer therapeutic based on the tumor suppressor microRNA-34. Cancer Res 2010;70:5923-5930.

11 Ji X, Wang Z, Geamanu A, Goja A, Sarkar FH, Gupta SV: Delta-tocotrienol suppresses Notch-1 pathway by upregulating miR-34a in nonsmall cell lung cancer cells. Int J Cancer 2012;131:2668-2677.

12 Vinall RL, Ripoll AZ, Wang S, Pan CX, deVere White RW: MiR-34a chemosensitizes bladder cancer cells to cisplatin treatment regardless of p53-Rb pathway status. Int J Cancer 2012;130:2526-2538.

13 Nakatani F, Ferracin M, Manara MC, Ventura S, Del Monaco V, Ferrari S, Alberghini M, Grilli A, Knuutila S, Schaefer KL, Mattia G, Negrini M, Picci P, Serra M, Scotlandi K: miR-34a predicts survival of Ewing's sarcoma patients and directly influences cell chemo-sensitivity and malignancy. J Pathol 2012;226:796805. 


\section{Cellular Physiology Cell Physiol Biochem 2018;48:87-98 \begin{tabular}{l|l|l}
\hline DOI: 10.1159/000491665 2018 & $\begin{array}{l}\text { C) 2018 The Author(s). Published by S. Karger AG, Basel } \\
\text { www.karger.com/cpb }\end{array}$
\end{tabular}

Liu et al.: MicroRNA-34a Attenuates Metastasis and Chemoresistance in Bladder Cancer Cells

14 He L, He X, Lim LP, de Stanchina E, Xuan Z, Liang Y, Xue W, Zender L, Magnus J, Ridzon D, Jackson AL, Linsley PS, Chen C, Lowe SW, Cleary MA, Hannon GJ: A microRNA component of the p53 tumour suppressor network. Nature 2007;447:1130-1134.

-15 Chang TC, Wentzel EA, Kent OA, Ramachandran K, Mullendore M, Lee KH, Feldmann G, Yamakuchi M, Ferlito M, Lowenstein CJ, Arking DE, Beer MA, Maitra A, Mendell JT: Transactivation of miR-34a by p53 broadly influences gene expression and promotes apoptosis. Mol Cell 2007;26:745-752.

-16 Duan K, Ge YC, Zhang XP, Wu SY, Feng JS, Chen SL, Zhang LI, Yuan ZH, Fu CH: miR-34a inhibits cell proliferation in prostate cancer by downregulation of SIRT1 expression. Oncol Lett 2015;10:3223-3227.

-17 Fan Y, Shen B, Tan M, Mu X, Qin Y, Zhang F, Liu Y: Long non-coding RNA UCA1 increases chemoresistance of bladder cancer cells by regulating Wnt signaling. Febs j 2014;281:1750-1758.

-18 Zhang Z, Chang Y, Zhang J, Lu Y, Zheng L, Hu Y, Zhang F, Li X, Zhang W, Li X: HMGB3 promotes growth and migration in colorectal cancer by regulating WNT/beta-catenin pathway. PLoS One 2017;12:e0179741.

19 Chen Z, Zhou L, Wang L, Kazobinka G, Zhang X, Han X, Li B, Hou T: HBO1 promotes cell proliferation in bladder cancer via activation of Wnt/beta-catenin signaling. Mol Carcinog 2017

20 Liu X, Liu X, Wu Y, Wu Q, Wang Q, Yang Z, Li L: MicroRNAs in biofluids are novel tools for bladder cancer screening. Oncotarget 2017;8:32370-32379.

-21 Blanca A, Cheng L, Montironi R, Moch H, Massari F, Fiorentino M, Raspollini MR, Scarpelli M, Lopez-Beltran A: Mirna Expression in Bladder Cancer and Their Potential Role in Clinical Practice. Curr Drug Metab 2017

-22 Pan J, Li X, Wu W, Xue M, Hou H, Zhai W, Chen W: Long non-coding RNA UCA1 promotes cisplatin/ gemcitabine resistance through CREB modulating miR-196a-5p in bladder cancer cells. Cancer Lett 2016;382:64-76.

-23 Amir S, Mabjeesh NJ: microRNA expression profiles as decision-making biomarkers in the management of bladder cancer. Histol Histopathol 2017;32:107-119.

-24 Homami A, Ghazi F: MicroRNAs as biomarkers associated with bladder cancer. Med J Islam Repub Iran 2016;30:475.

-25 Li HJ, Sun XM, Li ZK, Yin QW, Pang H, Pan JJ, Li X, Chen W: LncRNA UCA1 Promotes Mitochondrial Function of Bladder Cancer via the MiR-195/ARL2 Signaling Pathway. Cell Physiol Biochem. 2017;43:2548-2561.

26 Xiong Y, Wang L, Li Y, Chen M, He W, Qi L: The Long Non-Coding RNA XIST Interacted with MiR-124 to Modulate Bladder Cancer Growth, Invasion and Migration by Targeting Androgen Receptor (AR). Cell Physiol Biochem. 2017;43:405-418.

-27 Shang A, Yang M, Shen F, Wang J, Wei J, Wang W, Lu W, Wang C, Wang C: MiR-1-3p Suppresses the Proliferation, Invasion and Migration of Bladder Cancer Cells by Up-Regulating SFRP1 Expression. Cell Physiol Biochem. 2017;41:1179-1188.

28 Li P, Yang X, Cheng Y, Zhang X, Yang C, Deng X, Li P, Tao J, Yang H, Wei J, Tang J, Yuan W, Lu Q Xu X, Gu M: MicroRNA-218 Increases the Sensitivity of Bladder Cancer to Cisplatin by Targeting Glut1. Cell Physiol Biochem. 2017;41:921-932.

-29 Zhi Y, Pan J, Shen W, He P, Zheng J, Zhou X, Lu G, Chen Z, Zhou Z: Ginkgolide B Inhibits Human Bladder Cancer Cell Migration and Invasion Through MicroRNA-223-3p. Cell Physiol Biochem. 2016;39:1787-1794.

-30 Ghandadi M, Sahebkar A: MicroRNA-34a and its target genes: Key factors in cancer multidrug resistance. Curr Pharm Des 2016;22:933-939.

-31 Yu G, Yao W, Xiao W, Li H, Xu H, Lang B: MicroRNA-34a functions as an anti-metastatic microRNA and suppresses angiogenesis in bladder cancer by directly targeting CD44. J Exp Clin Cancer Res 2014;33:779.

-32 Zhang C, Yao Z, Zhu M, Ma X, Shi T, Li H, Wang B, Ouyang J, Zhang X: Inhibitory effects of microRNA-34a on cell migration and invasion of invasive urothelial bladder carcinoma by targeting Notch1. J Huazhong Univ Sci Technolog Med Sci 2012;32:375-382.

-33 Werner TV, Hart M, Nickels R, Kim YJ, Menger MD, Bohle RM, Keller A, Ludwig N, Meese E: MiR-34a-3p alters proliferation and apoptosis of meningioma cells in vitro and is directly targeting SMAD4, FRAT1 and BCL2. Aging 2017;9:932-954.

34 Hermeking H: The miR-34 family in cancer and apoptosis. Cell Death Differ 2010;17:193-199.

-35 Klaus A, Birchmeier W: Wnt signalling and its impact on development and cancer. Nat Rev Cancer 2008;8:387-398. 